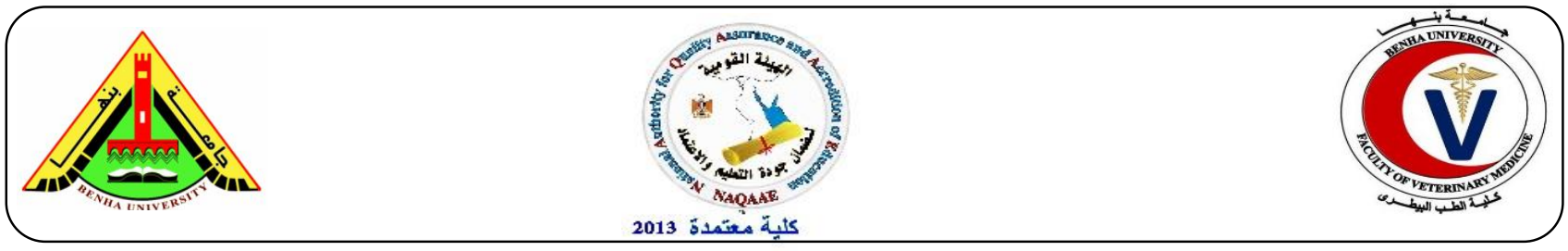

\title{
Full VP2 sequence analysis of Infectious Bursal Disease Virus (IBDV) in broiler chicken in Egypt
}

\author{
Gabr F. El-Bagoury ${ }^{1}$, Mahmoud M. Elsamaloty ${ }^{2}$, Ayman S. El-Habbaa ${ }^{1}$ and Naglaa A. Haggag ${ }^{3}$ \\ ${ }^{1}$ Department of Virology, Faculty of Veterinary Medicine, Benha University, Egypt \\ ${ }^{2}$ Animal Health Research Institute, Provincial Lab., Tanta, Gharbia, Egypt \\ ${ }^{3}$ National Laboratory for Veterinary Quality Control on Poultry Production, Animal Health Research Institute, \\ Dokki, Giza 12618, Egypt
}

\section{A B S T R A C T}

Infectious bursal disease virus (IBDV) is a highly infectious disease that severly affecting young chickens and alters the immune system. In this study, 32 bursae samples collected from different broiler flocks (from Gharbia, Behera, Menofia, and Kaferelsheikh) showed high mortality rate and bursal lesions during 2018 were examined. Obvious differences in genotyping between very virulent (vvIBD) and classical infectious bursal disease virus. Reverse transcriptase polymerase chain reaction (RT-PCR) was applied for IBD targeting the hyper variable region (HVR) of VP2 gene. The RT-PCR revealed that 20 samples positive, 10 representable samples were selected for genetic analysis from them 6 samples were selected for full VP2 geneticac analysis which revealed that these samples related to vvIBDV strains. The genotyping of Egyptian vvIBDV indicate massive evolution compared with previously isolated strains which indicate the persistence of vvIBDV in Egyptian poultry environment.

Keywords: IBDV, Virus isolation, RT-PCR, VP2 Sequencing, phylogeny.

(http://www.bvmj.bu.edu.eg) (BVMJ-35(2): 559-567, 2018)

al., 2008). The first report of acute

\section{INTRODUCTION}

Infectious bursal disease (IBD) is an acute and highly contagious viral disease of young chicks characterized mainly by severe lesions in the bursa of fabricious causing mortality and sever immunesuppression in chickens (Eterradossi et al., 2008). IBD virus belongs to family Birnaviridae with non-enveloped capsid. The first report in 1989, IBDV has two subtypes; variant and the other is classical subtype that has been subdivided into 3 pathotypes: attenuated, classical virulent, and very virulent (vvIBDV) (Jackwood et infectious bursal disease virus (vvIBDV) was in 1989 (Stuart, 1989), and since that time vvIBDV strains have been reported in many parts of the world (Van den Berg, 2000). In Egypt very virulent strains were reported since its first introduction in 1989 (El-Batrawi, 1990). Variant IBD strains were also reported in Egyptian flocks (Bekhit, 1998).

Severe mortalities and sever lymphoid depletion with bursal hemorrhages were the characteristics to the acute form of vvIBD in Australia (Ignjatovic et al., 2001). Clear differentiation in pathotyping was 
demonstrated between classical vIBD and vvIBDV strains (Ingrao et al., 2013; Sharma et al., 1989).

The IBDV genome is divided into segments $\mathrm{A}$ and $\mathrm{B}$ : segments $\mathrm{A}(3.4 \mathrm{~kb})$ and $\mathrm{B}$ (2.8 $\mathrm{kb})$. The large segment A encodes 4 viral proteins, the two capsid proteins VP2 (48 $\mathrm{kDa})$ and VP3 (32-35 $\mathrm{kDa})$, the viral protease VP4 (24 kDa), and a nonstructural protein VP5 (17-21 kDa). The smaller segment B encodes RNA-dependent RNA polymerase VP1 $(90 \quad \mathrm{kDa})$. Expression/deletion studies reported that VP2 aa positions 206 to 350 to represent a major conformational, neutralizing antigenic domain called hyper variable region (HVR) (Xu et al., 2011), which includes the most variable region important for cell antigenic and pathogenic characteristic variation. Most exchanges of e tamino acid residues in VP2 occur in the four hydrophilic loops of the viral capsid (Coulibaly et al., 2005). These exchanges indicate the selective pressure for the evolution of IBDV is directly focused on the capsid regions that are immediately exposed to the immune system (Durairaj et al., 2011). However, most of commercial broiler flocks were vaccinated against IBD, severe outbreaks were reported in Egypt, caused high mortalities, and have become a serious problem (El-Batrawi, 1990; Bekhit, 1998). RT-PCR has been used for amplification of sections of the IBDV genome. The VP2 gene is commonly studied because it encodes for the major protective epitopes, contains determinants for pathogenicity, and is highly variable among strains (Abdel-Alem, et al., 2003; Jackwood and Sommer-Wagner, 2006). The amino acids A222, I256 and I294 were reported to be unique to all known vvIBDV strains (Banda et al., 2004). In addition, the amino acids I242, I256, I294 and S299 were reported to be highly conserved among vvIBDV strains (Rudd et al., 2002). Presently, evidence of circulating variant IBDV strains was isolated from flocks vaccinated using classical IBDV vaccines. This study aims to determine the full VP2 genetic characterization of 6 selected isolates of the total $10 \mathrm{IBDV}$ isolates that have been obtained from different governorates in 2018 in Egypt using RTPCR and sequence analysis of HVR part of the VP2 gene.

\section{2- MATERIALS AND METHODS}

\subsection{Field samples}

Ten (10) chicken broiler farms in different Egyptian Governorates showed different mortality rates associated with bursal lesions during 2018.

\subsection{Molecular detection by RT-PCR}

10 bursae were collected for viral detection by RT-PCR. RNAs were extracted from the Bursal homogenates [one part of each bursa sample disrupting in sterile saline $(1: 1)]$ using QiAmp Viral RNA Mini kit (Qiagen GmbH, Hilden, Germany) according to the manufacturer's instructions. A set of primers were used for the RT-PCR reaction and for the subsequent sequence analysis using forward and reverse PCR primers for amplification of a $620 \mathrm{bp}$ fragment .

Forward primer: [AUS GU: 5'-TCA CCG TCC TCA GCTTAC CCA CAT C-3'].

Reverse primer: [AUS GL: 5'-GGA TTT GGG ATC AGCTCG AAG TTG C-3'] PCR amplification was performed by using Qiagen One Step Enzyme Mix according to the manufacturer's instructions. The VP2F primer was used to reverse transcribe IBDV RNA to cDNA. After initial denaturation at 
$94^{\circ} \mathrm{C}$ for $5 \mathrm{~min}, 35$ cycles consisting of denaturation at $95^{\circ} \mathrm{C}$ for $40 \mathrm{sec}$, annealing at $59^{\circ} \mathrm{C}$ for $1 \mathrm{~min}$, extension at $72^{\circ} \mathrm{C}$ for 1 min and finally one step of extension was performed at $72^{\circ} \mathrm{C}$ for $10 \mathrm{~min}$. After amplification, $10 \mu \mathrm{l}$ of PCR products were analyzed by electrophoresis on a $1.5 \%$ agarose gel containing ethidium bromide, the DNA fragments were 620bp in length.

6 samples were selected for full VP2 sequence analysis using forward and reverse PCR primers for amplification of a $1200 \mathrm{bp}$ fragment. The first primer ( VP2 F, VP2 R) used for the first part of VP2 gene (F1 to R491) while the second primer (VP2 F, VP2 R) used for the last part of the VP2 gene ( F673 to R1309) respectively. After initial denaturation at $94^{\circ} \mathrm{C}$ for $5 \mathrm{~min}, 35$ cycles consisting of denaturation at $95^{\circ} \mathrm{C}$ for $15 \mathrm{sec}$, annealing at $56^{\circ} \mathrm{C}$ for $30 \mathrm{sec}$, extension at $61.5^{\circ} \mathrm{C}$ for $2 \mathrm{~min}$ and finally one step of extension was performed at $53^{\circ} \mathrm{C}$ for $10 \mathrm{~min}$. After amplification, The PCR products were inoculated in agarose gel placed in the electrophoresis chamber to determine the base pairs of the PCR product (1300) bp which could be visualized by the presence of marker (Qiagen) and using Gel documentation system. (Biometra).

Forward primer: [AUS GU: 5'- ATG ACA AAC CTG CAA GAT CAA -3'].

Reverse primer: [AUS GL: 5'- TCT GGG CCT GTC ACT GCT G -3’]

Forward primer: [AUS GU: 5'- GTA ACA ATC ACA CTG TTC TCA GC -3'].

Reverse primer: [AUS GL: 5'- AAT GCT CCT GCA ATC TTC AG -3']

\subsection{Sequence for HVR of VP2 gene}

Gel containing DNA band of the expected size (620 bp) was excised and purified with the QIAquick Gel Extraction Kit (Qiagen) according to the manufacturer instruction. The purified PCR products were sequenced directly using the ABI PRISM. Big Dye TM Terminators v3.1 Cycle Sequencing Kit (Applied Biosystems, Foster City, CA, USA), The products of the sequencing reactions were cleaned-up using Centrisep purification kit Analyzer (Applied Biosystem, CA - USA). The purified products were sequenced directly using the ABI (Applied Biosystems, Foster City, CA, USA) and the ABI PRISM 3130 genetic analyzer (Applied Biosystems) The phylogram was drawn using also MEGA 5 software. The alignment of the viruses in the study was done using DNAstar MegAlign software. Egyptian viruses and other international reference strains from the Genbank and were available from the National Center for Biotechnology Information (NCBI) infectious bursal disease viruses resource (http://www.ncbi). Finally the identity percent and divergence between all viruses was carried out.

\section{3- RESULTS}

3.1. IBDV detection by Reverse Transcription RT-PCR

Bursal samples tested with RT-PCR, showed that 10 samples were positive. Ten representable samples from the positive samples were selected for RT-PCR showed specific bands at $620 \mathrm{bp}$ on $1.5 \%$ agarose gel stained with ethidium bromide (Figure.1).

\subsection{Phylogenic characterization of VP2 gene of IBDV}

Sequence analysis of the PCR products revealed 5 (IBD GH-3, KS-6, Mnf-10, Beh21 and Mnf-24) cases characterized as very 
virulent and cases were similar to classic (vaccine) strains of IBDV, (IBD GH-1) similar to D78 vaccine, (IBD GH-3, KS-6, IBD Mnf-10, Beh-21, Mnf-23 and Mnf-24) similar to Giza2008, as shown in the following phylogenetic tree.

\subsection{Sequence analysis of full VP2 region of IBDV}

A $1200 \mathrm{bp}$ fragment of the full VP2 gene of the isolated IBDV 2018 from different governorates was subjected to sequencing and sequence alignment with other Egyptian and vaccination IBDV strains. A $620 \mathrm{bp}$ fragment of VP2 gene consensus of 110 amino acid residues in the hyper variable region were used for sequence analysis of the deduced amino acid sequences of the isolates (IBDV 2018) correspond to the region from AA residue 216 to AA residue 325. Substitution mutations were observed in 5 isolates at Y220F, P222A, V256I, L294I and N299S which are highly conserved with Egyptian vvIBD starins (Giza2000, Giza2008 and
Beh.2003) in comparison with other vvIBDV, while 1 isolate belonged to classical IBDV (similar to vaccine strains). Ssp I, T, and S restriction sites in ALL vv strains corresponds to the substitution at residue (leucine L 294I isoleucine), (Alanine A to 52T Threonine) and (glycine $\mathrm{G} 76 \mathrm{~S}$ serine) at 76 ) respectively as shown in figure 3

All Ssp restriction sites on VP2 was previously reported to be characteristic of vvIBDV strains as shown in the next aligment report. While Changed in the nucleotide Thiamine $(\mathrm{T})$ to Cytosine $(\mathrm{C})$ at site 1155 have not changed the AA Valine (V) at 384 site and also it resembled to that of vv IBDV.

The Similarity between VV strains under study and Egyptian classic strain was ranged between (92 to 96\%) and with Giza 2008 ranged between (95 to 100\%). Finally, it was found that Classic strains (IBD GH1) similar to Kal2001, Classic strains (IBD Ks-11) similar to CEVAC IBD L (figure 4).

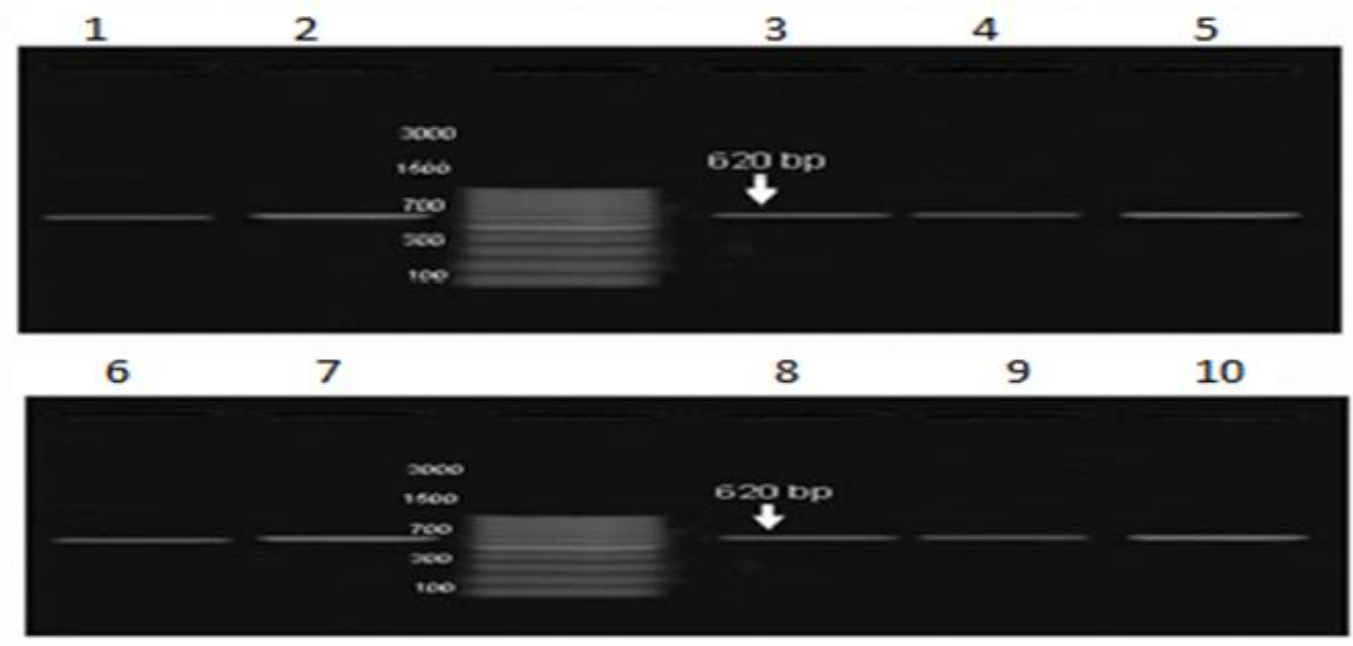

Figure.1. Agarose gel electrophoresis pattern of the amplified products for detection of the IBD virus VP2gene for local isolates. It revealed the presence of specific PCR product at the correct expected size of the VP2 gene (620 bp). 


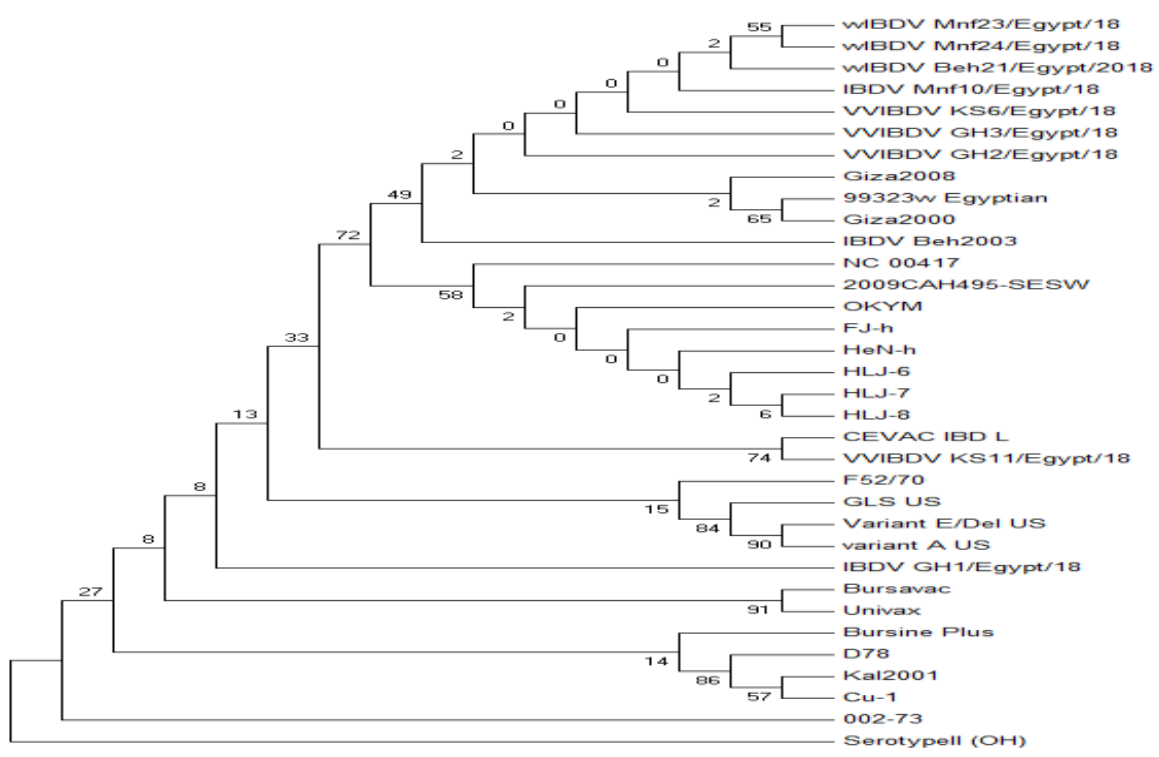

Figure 2: Phylogenetic analysis of the recent Egyptian isolates in comparison with other isolates published in Genbank bank.
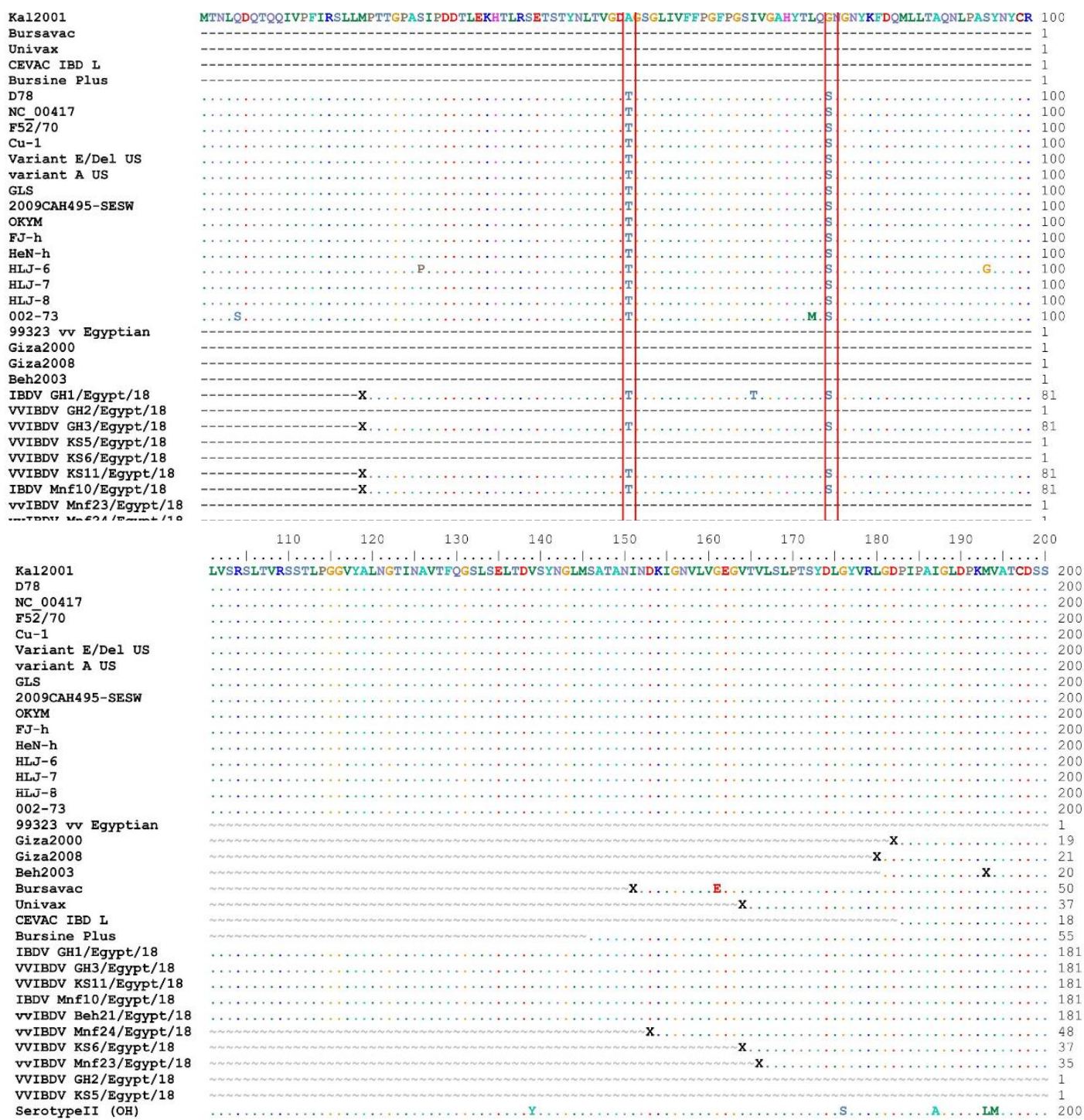

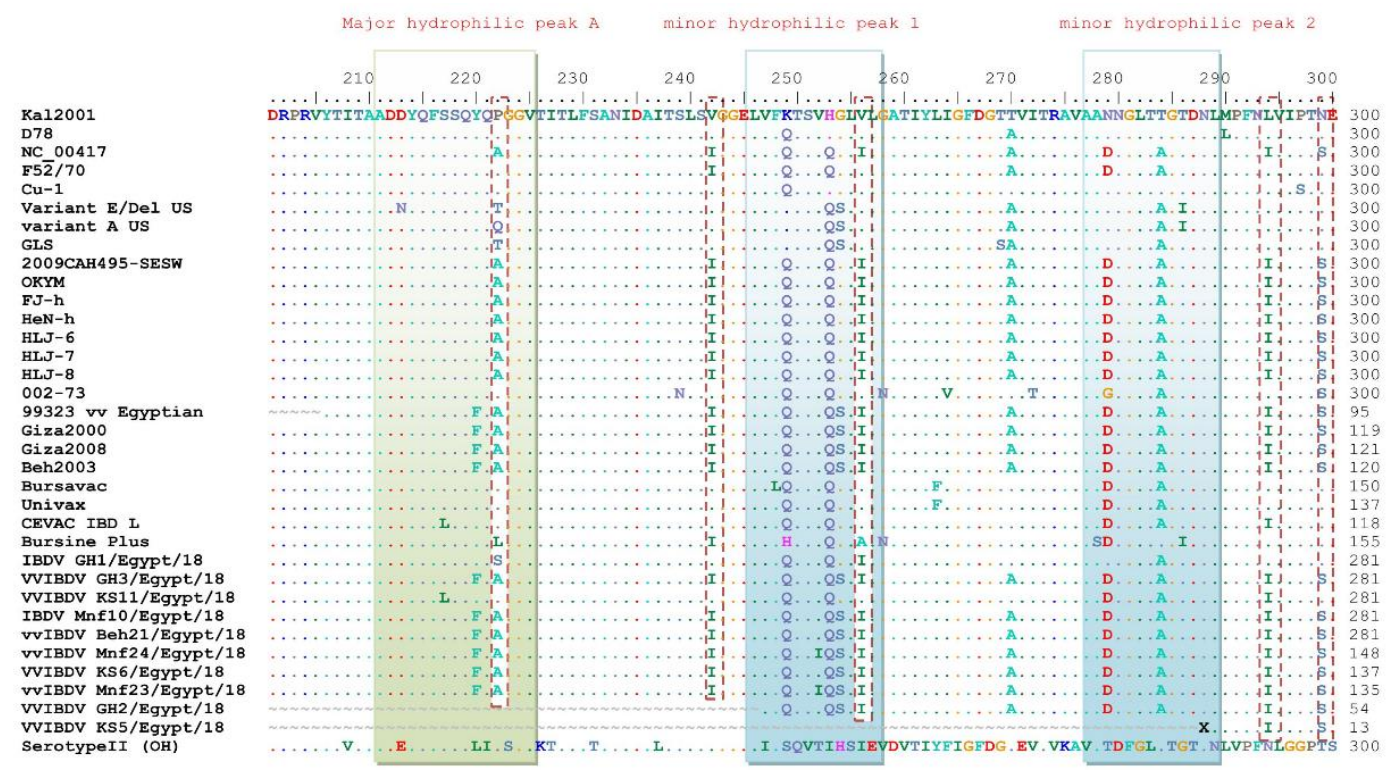

Figure 3: AA alignment of full VP2 gene of IBDV
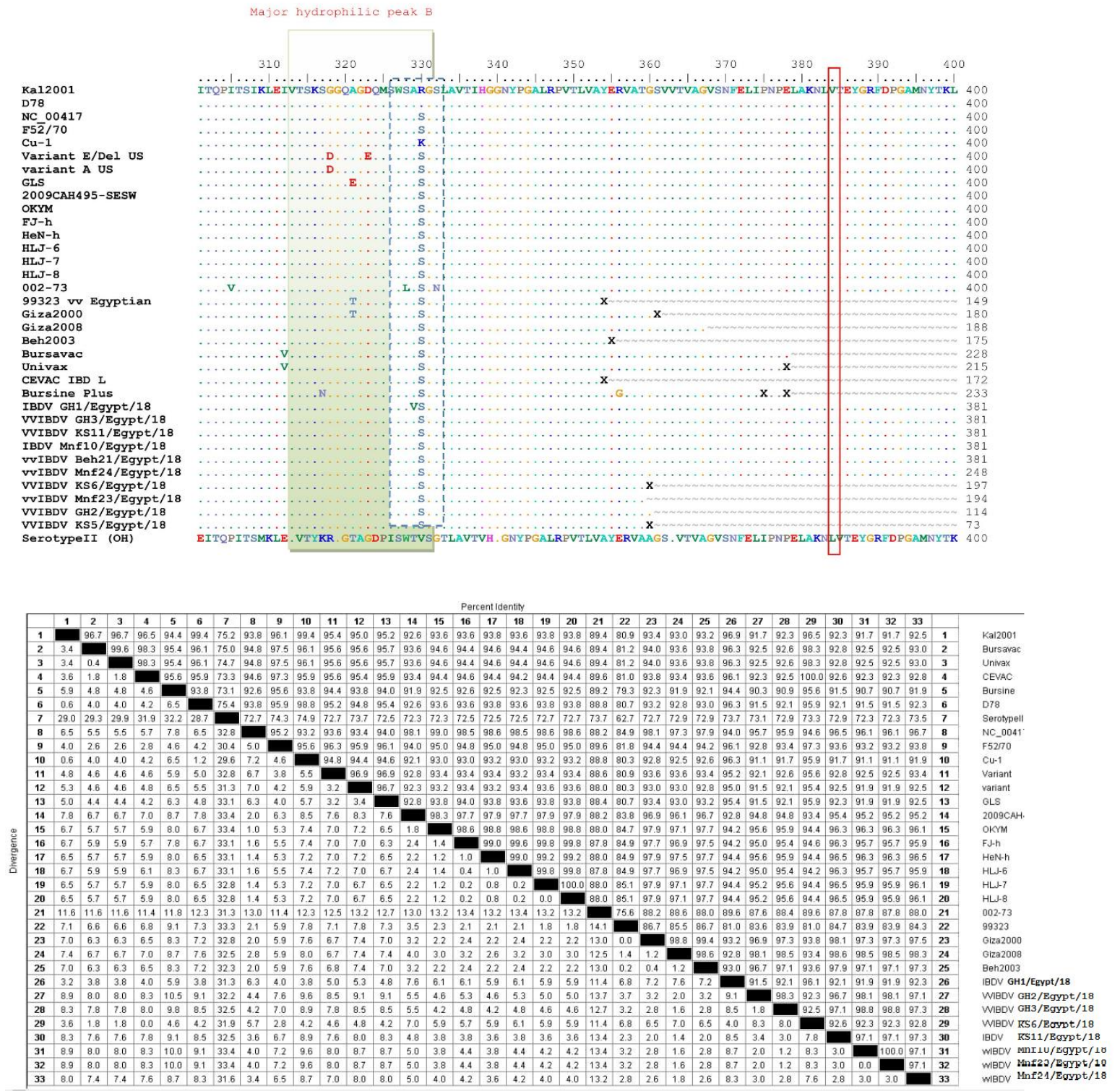

Figure 4: The similarity between IBDV isolates and other Egyptian and representative reference strains. 


\section{DISCUSSION}

Infectious bursal disease virus is a serious problem in Egypt as it did not in other poultry producing countries all over the world. A preventive program is crucial to avoid virus continuous spread and disease appearance .The clinical diagnosis of the sever forms of IBD depend on the observation of the symptoms and postmortem examination of the lesions on the bursa of Fabricius. (Hussein et al., 2003). Although all birds had been vaccinated against IBD high morbidity and mortality was observed in poultry farms in different governorates, so this study was conducted to isolate and molecular characterization of the causative agent.

Regarding trials of virus isolation on emberyonated chicken embryo (ECE); it was found that embryo deaths were recorded by the 2 days post egg inoculation through the dropped chorioalantoic membrane showed changes in harvested dead embryos were varied from severe congestion and hemorrhage in the feather tracts of the skin and toes to some showed small congestion on the head and toes. In this respect (Hitchner 1970) and (Kosters et al., 1971) used ECE to isolate and propagate IBDV and (Lukert and Saif 2003) stated that variant IBDV do not kill the embryos and rarely induce congestion or hemorrhages. Embryo lesions characteristic of variant IBDV infection include cerebral and abdominal edema, stunting, off-white or cream-colored skin and feathers, necrosis and bile stasis of the liver, and splenomegaly.

Molecular approaches allow the identification, characterization and differentiation of IBDV strains circulating in chicken populations and associate recent and past isolates (Le Nouen et al., 2005). Detection of IBDV by RT-PCR of HVR (216 to 325 aa) that contain the most informative genetic data regarding strain variability. It was chosen for sequence analysis to characterize IBDV strains molecularly, allowing analysis of variations that happen naturally or by attenuation in different strains, leading to changes in antigenicity and/or virulence (Jackwood and Sommer-Wagner, 2006; Banda et al., 2003). In the present study, 32 bursal samples were collected from different governorates from farms with clinical signs and lesions that were characteristic of gumboro infection and analyzed for presence and determination the genotype of IBDV, 10 representable samples from 20 positive samples were identified for IBDVs on the basis the partial amplification of VP2 by RT-PCR, 6 representable samples were selected for identification for IBDVs on the basis of full VP2 by RT-PCR.

A comparative alignment and phylogenetic analysis of the hypervariable domain of the VP2 grouped the IBDV local isolates into subgroups, VV strains differed from the previously isolated Kal 2001 classical Egyptian starin by having alanine (A) residue at position 222 instead of proline $(\mathrm{P})$ and asparagine $(\mathrm{N})$ residue at position 279 instead of aspartic acid (D). With a comparative alignment of full VP2 gene analysis of the selected isolates it was found also having threonine $(\mathrm{T})$ residue at position 52 instead of alanine (A) and glycine $(G)$ residue at position 76 instead of serine (S). The reported mutation in these isolates may be as results of the extensive abuse of IBDV vaccines as well as the heavily use of IBD different vaccination programs. The reported mutation in these isolates may be as results of the extensive 
abuse of IBDV vaccines as well as the heavily use of IBD different vaccination programs.

In addition, It was reported that the major Hydrophilic region (peak A 212-224) to be important in the binding of neutralizing monoclonal antibodies (Mabs) and were presumed to be the dominant parts of the neutralizing domain. Therefore, variation in this region is likely to induce significant antigenic variation (Domanska et al., 2004; Eterradossi et al., 1998). In this study, 6 very virulent isolates have one amino acid substitution (Y220F), This amino acid substitution may affect virus antigenicity change which may has an important role in increasing virulence that may cause disease in the presence of high maternal antibody.

Residues present in the full VP2 region at position (P222A, V256I, L294I, and N299S) showed to be unique for all vvIBDV strains as compared to classical strains (Jackwood et al., 2008; Naglaa et al., 2015), sequence analysis of 6 vvIBD show that The same amino acids at position 222A, 256I, 294I, 299S, 279D, 76G and $53 \mathrm{~T}$.

Amino acids found at positions 253 and 284 were found to be responsible for pathogenicity and are unique to highly virulent IBDVs (Brandt et al., 2001; Islam et al., 2001). It was supposed that they were also involved in cell culture adaptation, where (Q253H, A284T) are specific amino acids for cell tropism (Van Loon et al., 2002; Naglaa et al., 2015). All studied isolates show (253Q, 284A) these results suggested the difficulty of cell culture of these isolated strains. Strains, which have glutamine at, position 253 reported to be high pathogenicity than those with a histidine at position 253. Recently, special attention was given to amino acids at position 253 where histidine or glutamine is found. Because of the intensive vaccination programs performed in the field with live attenuated viruses, there is a possibility that the viruses used mutate and subsequently change their pathogenic potential (Zierenberg et al., 2001; Naglaa et al., 2015).

A specific SspI site on VP2 has previously been identified in all vvIBDV strains (Jackwood et al., 2008). Consequently, this SspI site has been used as a genetic marker to predict a very virulent phenotype that must be confirmed by in vivo studies. However, not all vvIBDV have this marker and some non-vvIBDV strains have been found to contain the SspI marker (Sapats and Ignjatovic, 2002). It is interesting that all vvIBDV isolates under study had this restriction site while it was not observed in vaccine (classic) strain.

\section{CONCLUSION}

The presence of six viruses of very virulent strain indicate circulation of the field viruses in poultry flocks, while two viruses of vaccine strains indicate the intensive use of vaccination programs performed with live intermediate-plus and intermediate viruses may lead to the possibility of emergence of mutants and subsequently they constantly change their pathogenic potential and that require review the vaccination programs in Egypt.

\section{REFERENCES}

Allan, W. H., Faragher, J. T. and Cullen, G. A. (1972). Immunosuppression by the infectious bursal agent in chickens immunised against Newcastle disease. Vet Rec 90, 511-2. 
Banda AP and El-Attrache, V. ( 2003). Molecular characterization of infectious bursal disease virus from commercial poultry in the United States and Latin America. J.Avian Dis 47(1), 87-95.

Chettle, N., Stuart, J. C. and Wyeth, P. J. (1989). Outbreak of virulent infectious bursal disease in East Anglia. Vet Rec $125,271-2$.

Dobos, P., Hill, B. J., Hallet, R., Kells, D. T., Becht, H. and Teninges, D. (1979). Biophysical and biochemical characterization of five animal viruses with bisegmented double-stranded RNA genomes. J. Virol 32, 593-605.

Domanska, K.; Mato, T.; Rivallan, G.; Smietanka, K.; Minta, Z.; de Boisseson, C.; Toquin, D.; Lomniczi, B.; Palya, V. and Eterradossi, N. (2004): Antigenic and genetic diversity of early European isolates of Infectious bursal disease virus prior to the emergence of the very virulent viruses: early European epidemiology of Infectious bursal disease virus revisited? Archives of virology 2004, 149 (3), 465-80.

El-Bagoury, G. F., E. El-Nahas, \& A. ElHabbaa .(2015): Isolation and molecular characterization of IBDV from Qualubyia governorate, Egypt, Benha Veterinary Medical Journal, 2015: VOL. 28, NO. 2:283-294

Eterradossi, N.; Arnauld, C.; Toquin, D. and Rivallan, G. (1998): Criticalamino acid changes in VP2 variable domain are associated withtypical and atypical antigenicity in very virulent infectious bursaldisease viruses. Archives of virology 1998; 143: 1627-36.
Hanson, B. S. (1967). Post-mortem lesions diagnostic of certain poultry diseases. Vet Rec 80, 109-19.

Hitchner, S. B. (1970). Infectivity of infectious bursal disease virus for embryonating eggs. Poult. Sci. 49, 511 516.

Hudson, P. J., McKern, N. M., Power, B. E. and Azad, A. A. (1986). Genomic structure of the larger RNA segment of infectious bursal disease virus. Nucl. Acid Res 14, 5001-5012.

Hussein AH, Aly AN, Sultan H and M., A.-S. (2003). Transmissible viral pronventriculitis and stunting syndrome in broiler chicken in Egypt. 1. Isolation and characterized of variant infectious bursal disease virus. Vet Med J Giza 51(3), 445-62.

Islam, M. R.; Zierenberg, K.; Eterradossi, N.; Toquin, D.; Rivallan, G. and Muller, $\mathrm{H}$. (2001): Molecular and antigenic characterization of Bangladeshi isolates of infectious bursal disease virus demonstrate their similarities with recent European, Asian and African very virulent strains. Journal of veterinary medicine. $\mathrm{B}$, Infectious diseases and veterinary public health 2001, 48 (3), 211-21.

Jackwood, D.J. and Sommer-Wagner, S. (2006): Molecular studies on suspect very virulent infectious bursal disease virus genomic RNA samples. Avian Diseases 2006, 49(2): 246-251.

Jackwood, D. J., Sreedevi, B., LeFever, L. J. and Sommer-Wagner, S. E. (2008). Studies on naturally occurring infectious bursal disease viruses suggest that a single amino acid substitution at position 253 in VP2 
increases pathogenicity. Virology 377, 110-6.

Kosters, J. and Paulsen, J. (1971). [Multiplication of the causative agent of infectious bursitis in young fowls (Gumboro disease) in chick embryo kidney cell cultures]. Zentralbl Veterinarmed B 18, 366-72.

Le Nouen, C., Rivallan, G., Toquin, D. and Eterradossi, N. (2005). Significance of the genetic relationships deduced from partial nucleotide sequencing of infectious bursal disease virus genome segments A or B. Arch Virol 150, 31325.

Lukert, P. D. and Saif, Y. M. (2003). Infectious Bursal Disease In: Diseases of Poultry, 11th ed. Y. M. Saif, H. J. Barnes., A. M. Fadly., J. R. Glisson., L. R. McDougald., and D. E. Swayne., eds. Iowa State Press, Ames, Iowa. pp., 161-179.

McFerran, J. B., McNulty, M. S., McKillop, E. R., Connor, T. J., McCracken, R. M., Collins, D. S. and Allan, G. M. (1980). Isolation and serological studies with infectious bursal disease viruses from fowl, turkeys and ducks: demonstration of a second serotype. Avian Pathol 395-404, 9.

Metwally, A., Yousif, A., Shaheed, I., Mohammed, W., Samy, A. and Reda, I. (2009). Re-Emergence of Very Virulent IBDV in Egypt. International Journal of Virology 5, 1-17.

Muller, H., Islam, M. R. and Raue, R. (2003). Research on infectious bursal disease-the past, the present and the future. Vet Microbiol 97, 153-65.
Mundt, E. and Muller, H. (1995). Complete nucleotide sequences of 5'- and 3'noncoding regions of both genome segments of different strains of infectious bursal disease virus. Virology 209, 10-8.

Naglaa M. Hagag; Mohamed A. Soliman; Abdel Satar Arafa; Ali Zanaty; Ahmed M. Erfan and Mohamed K. Hasan. (2015). Genetic characteristics of infectious bursal disease virus in Egypt from 2012 to 2014. Assiut Vet. Med. J. Vol. 61 No. 147, 43 - 48

Rosenberger, J. K., Cloud, S. S., Gelb, J. J., Odor, E. and Dohms, J. E. (1985). Sentinel bird survey of Delmarva broiler flocks. Proc. 20th Nat. Meet. Poult. Health Condemn, pp, 94-101.

Van den Berg, T. P., Gonze, G. M. and Meulemans, G. (1991). Acute infectious bursal disease in poultry: isolation and characterization of a highly virulent strain. Avian Pathol 20, 133-143.

Van Loon, A.A.; de Haas, N.; Zeyda, I. and Mundt, E. (2002): Alteration of amino acids in VP2 of very virulent infectious bursal disease virus results in tissue culture adaptation and attenuation in chickens. The Journal of general virology 2002, 83 (Pt 1), 121-9.

Zierenberg, K.; Raue, R. and Muller, H. (2001): Rapid identification of "very virulent" strains of infectious bursal disease virus by reverse transcriptionpolymerase chain reaction combined with restriction enzyme analysis. Avian Pathology 2001; 30: 55-62. 